\title{
Quantum Chemical Modeling of Photoabsorption Properties of Two- and Three-Nitrogen Vacancy Point Defects in Diamond
}

\author{
A. S. Zyubin, ${ }^{\dagger}$ A. M. Mebel, ${ }^{*, *}$ M. Hayashi, ${ }^{\S}$ H. C. Chang, ${ }^{\|}$and S. H. Lin ${ }^{\perp}$ \\ Institute of Problems of Chemical Physics, Russian Academy of Sciences, Chernogolovka, \\ Moscow Region 142432, Russia, Department of Chemistry and Biochemistry, Florida International University, \\ Miami, Florida 33199, Center for Condensed Matter Science, National Taiwan University, Roosevelt Road, \\ Section 4, Taipei, Taiwan, 10764, Institute of Atomic and Molecular Sciences, Academia Sinica, \\ P.O. Box 23-166, Taipei 106, Taiwan, and Institute of Molecular Sciences and Department of Applied \\ Chemistry, National Chiao-Tung University, Hsinchu, Taiwan
}

Received: February 11, 2009; Revised Manuscript Received: May 4, 2009

\begin{abstract}
Quantum chemical calculations of the geometric and electronic structures and vertical transition energies for several low-lying excited states of the neutral and negatively charged vacancy-related point defects in diamond containing two and three nitrogen atoms $\left(\mathrm{N}_{2} \mathrm{~V}^{0}, \mathrm{~N}_{2} \mathrm{~V}^{-}\right.$, and $\left.\mathrm{N}_{3} \mathrm{~V}^{0}\right)$ have been performed employing various theoretical methods (time-dependent density functional theory, equation-of-motion coupled cluster, and multireference perturbation theory) and different basis sets and using $\mathrm{C}_{21} \mathrm{H}_{28}, \mathrm{C}_{35} \mathrm{H}_{36}$, and $\mathrm{C}_{51} \mathrm{H}_{52}$ finite model clusters. In the ground states, the vacancy-related atoms are found to be shifted away from the vacancy center by $\sim 0.1 \AA$, whereas the positions of atoms from the second layer around the vacancy remain nearly unchanged, indicating a local character of geometry relaxation due to defects. The lowest excited states are formed with participation of the stretched $\left(\mathrm{N}_{2} \mathrm{~V}\right)$ or broken $\left(\mathrm{N}_{3} \mathrm{~V}\right) \mathrm{C}-\mathrm{C}$ bond and nonbonding combinations of nitrogen lone pairs as donors, with the $\mathrm{C}-\mathrm{C}$ antibonding molecular orbital (MO) in $\mathrm{N}_{2} \mathrm{~V}^{0}$, broken $\mathrm{C}-\mathrm{C}$ bond in $\mathrm{N}_{3} \mathrm{~V}^{0}$, and diffuse vacancy-related MOs serving as acceptors. Normally, the first excited states have a valence character, but the diffuse states are rather close in energy, especially for $\mathrm{N}_{3} \mathrm{~V}^{0}\left(2^{2} \mathrm{~A}_{1}\right.$ and $1^{2} \mathrm{E}$ excited states). The first optically active excitation in the $\mathrm{N}_{2} \mathrm{~V}^{0}$ defect with the calculated energy of $\sim 2.6 \mathrm{eV}$ (in close agreement with the experiment) is formed by the electronic transition from the stretched $\mathrm{C}-\mathrm{C}$ bond to the antibonding $\mathrm{C}-\mathrm{C}$ MO, with an additional contribution from the combination of nitrogen lone pairs. For the negatively charged $\mathrm{N}_{2} \mathrm{~V}^{-}$system, the lowest excitation to the $1^{2} \mathrm{~A}_{1}$ state is predicted to occur from the singly occupied antibonding $\mathrm{b}_{1} \mathrm{MO}$ to the empty diffuse $\mathrm{a}_{1}$ orbital, but the CASPT2 calculated excitation energy, $\sim 0.9 \mathrm{eV}$, underestimates the experimental zero phonon line observed at $1.26 \mathrm{eV}$. The lowest excited states of $\mathrm{N}_{3} \mathrm{~V}^{0}, 2^{2} \mathrm{~A}_{1}$, and $1^{2} \mathrm{E}$ correspond to transitions from the singly occupied $\mathrm{MO}$ (SOMO) to the diffuse lowest vacant orbital and from the nonbonding combination of nitrogen lone pairs to SOMO, respectively, and have similar energies of about 3.1-3.3 eV, in agreement with the experimental photoabsorption band maximum at $\sim 3 \mathrm{eV}$.
\end{abstract}

\section{Introduction}

Pure diamonds possess high transparence in the infrared (IR) and visible spectral ranges, but an appearance of atomic impurities in combination with vacancies can create a variety of color centers. More than 500 of such structures are known at present. ${ }^{1-3}$ The dominant impurity in natural and synthetic diamonds is nitrogen. ${ }^{4-6}$ Aggregations of nitrogen admixtures with a vacancy creates thermally stable structures possessing high quantum efficiency up to temperatures above $500 \mathrm{~K}$. Combinations of the vacancy with one, two, or three $\mathrm{N}$ atoms are known. These centers exhibit $\mathrm{C}_{3 \mathrm{v}}$ or $\mathrm{C}_{2 \mathrm{v}}$ point symmetry and are denoted as NV (nitrogen vacancy), H3 (2NV), H2 $\left(2 \mathrm{NV}^{-}\right)$, and N3 (3NV). Diamonds with these color centers have caused substantial interest with researchers because of their exceptional properties due to these defects in combination with

\footnotetext{
* To whom correspondence should be addressed. E-mail: mebela@fiu.edu

$\uparrow$ Russian Academy of Sciences.

* Florida International University.

$\S$ National Taiwan University.

"Academia Sinica.

${ }^{\perp}$ National Chiao-Tung University.
}

outstanding hardness, high damage threshold, chemical and thermal stability, and thermal conductivity of the host crystal. ${ }^{2,3}$

The nitrogen vacancy (NV) defect possessing a particularly strong electronic transition is the most common and attractive to researchers, as it allows optical detection of individual centers. ${ }^{7}$ This defect is an example of an individual quantum object with potential applications to quantum information processing. Additionally, these objects possess a remarkable photo and chemical stability, and therefore, they have been proposed as light sources for high-resolution scanning probe microscopy and quantum cryptography, ${ }^{7-10}$ where a stable single-photon source with a high quantum yield is required. Recently, nanosized diamond powders containing NV defects were suggested as cellular biomarkers. ${ }^{11}$ The NV defect center in diamond has been extensively investigated experimental$1 y^{2,3,7-10,12-33}$ and theoretically. ${ }^{34-41}$

The studies (especially theoretical) of the defects containing two and three $\mathrm{N}$ atoms $(\mathrm{H} 3, \mathrm{H} 2$, and $\mathrm{N} 3$ ) are scarce, despite the fact that these centers also exhibit remarkable properties. It was proposed that N3 with a zero phonon line (ZPL) of $\sim 2.8$ $\mathrm{eV}$ and a photoabsorption (PA) band maximum at $\sim 3 \mathrm{eV}$ has 
the electronic structure qualitatively similar to that of $\mathrm{NV}^{-}$; in particular, the ground state is of the A-type, whereas the $\mathrm{E}$ and A excited states have a small energy difference, with the A state being slightly lower. ${ }^{2}$ Theoretical calculations ${ }^{37,42}$ employing the local spin density approximation (LSDA) density functional approach did not show such states; instead, the results suggested an excitation to a shallow $\mathrm{a}_{1}$ trap localized outside the vacancy (a charge transfer transition). Clearly, calculations utilizing more sophisticated theoretical methods and with larger basis sets would be informative. For the $\mathrm{H} 3$ defect, the experimentally observed PA band peaked at $2.58 \mathrm{eV}^{2}$, and ZPL was observed at $\sim 2.33$ or $2.46 \mathrm{eV} .^{2,27}$ Several additional nonluminescent lines around $3.4 \mathrm{eV}$ (the so-called H13 system) were also found and attributed to the transitions from the ground state to the higherlying excited states of the $\mathrm{N}_{2} \mathrm{~V}^{0}$ defect. An absorption and photoluminescence (PL) system $\mathrm{H} 2$, with a $\mathrm{ZPL}$ at $1.26 \mathrm{eV}$, was associated with $\mathrm{N}_{2} \mathrm{~V}^{-} \cdot{ }^{27}$ Clearly, the optical properties of the defects with two and three nitrogen atoms differ from the properties of the $\mathrm{NV}^{-}$and $\mathrm{NV}^{0}$ defects. For instance, maxima of the PA and PL bands for $\mathrm{NV}^{-}$have been observed near 2.15 and $1.75 \mathrm{eV},{ }^{21}$ respectively, whereas the $\mathrm{ZPL}$ energy for $\mathrm{NV}^{0}$ has been found around $2.16 \mathrm{eV} .^{24,25}$ Apparently, broken $\mathrm{C}-\mathrm{C}$ bonds play a key role in the formation of colored centers in the vacancy-related systems. As compared to the NV defect, the appearance of additional $\mathrm{N}$ atoms around the vacancy alters the amount of such bonds from three to two to one, creating new combinations of active orbitals involved in lowlying electronic transitions in these centers responsible for their optical properties. In other words, replacing $\mathrm{C}$ atoms around the vacancy with nitrogen atoms changes wave functions of the ground and excited states. Quantum chemical calculations would be useful for elucidating the electronic structure of the defects and interpreting available experimental data.

However, because of the presence of highly stretched or broken bonds at the vacancy, one can expect that these defects would possess complicated, multideterminant wave functions, especially for excited electronic states. Hence, the modeling should be based on multireference ab initio methods such as, for instance, CASSCF (MCSCF), MRCI, and CASPT2. In our previous works, ${ }^{40,41}$ we investigated the NV defects with a single $\mathrm{N}$ atom, and the goal of the present paper is modeling of photoadsorption properties of the nitrogen vacancy defects with two and three $\mathrm{N}$ atoms.

Choice of Model Clusters and Calculation Details. Quantum chemical calculations of a diamond fragment and the $\mathrm{N}_{2} \mathrm{~V}$ and $\mathrm{N}_{3} \mathrm{~V}$ defects incorporated in it were carried out using the same three types of defectless model clusters as in our previous works, ${ }^{40,41}$ i.e., $\mathrm{C}_{21} \mathrm{H}_{28}$ (A1), $\mathrm{C}_{35} \mathrm{H}_{36}$ (A2), and $\mathrm{C}_{51} \mathrm{H}_{52}$ (A3) with termination of broken boundary bonds by $\mathrm{H}$ atoms (Figure 1). The vacancy was formed by removing the central $\mathrm{C}$ atom from the defectless cluster, and $\mathrm{N}$ atoms were inserted in the first coordination shell around the vacancy center. In the first system, the central atom is surrounded by two carbon shells forming a $\mathrm{C}_{17}$ system, but in this case, it is impossible to terminate all boundary bonds by $\mathrm{H}$ atoms, as some centers become very close to each other. This difficulty can be overcome by adding four $\mathrm{C}$ atoms with the same bond distances and bond angles as those in diamond but with torsion angles shifted by 60 degrees, e.g., the $\mathrm{C}_{21} \mathrm{H}_{28}$ cluster, where boundary $\mathrm{C}$ atoms have two $\mathrm{CH}$ bonds each. Another, but more expensive way to solve this problem is to use a larger $\mathrm{C}_{35} \mathrm{H}_{36}$ cluster, where $\mathrm{C}$ atoms from the second shell each have one $\mathrm{CH}$ bond. In the $\mathrm{C}_{51} \mathrm{H}_{52}$ cluster, all $\mathrm{C}$ atoms from the second shell have $\mathrm{C}-\mathrm{C}$ bonds only; to avoid crowding of boundary $\mathrm{H}$, we used the same approach as that for the $\mathrm{C}_{21} \mathrm{H}_{28}$

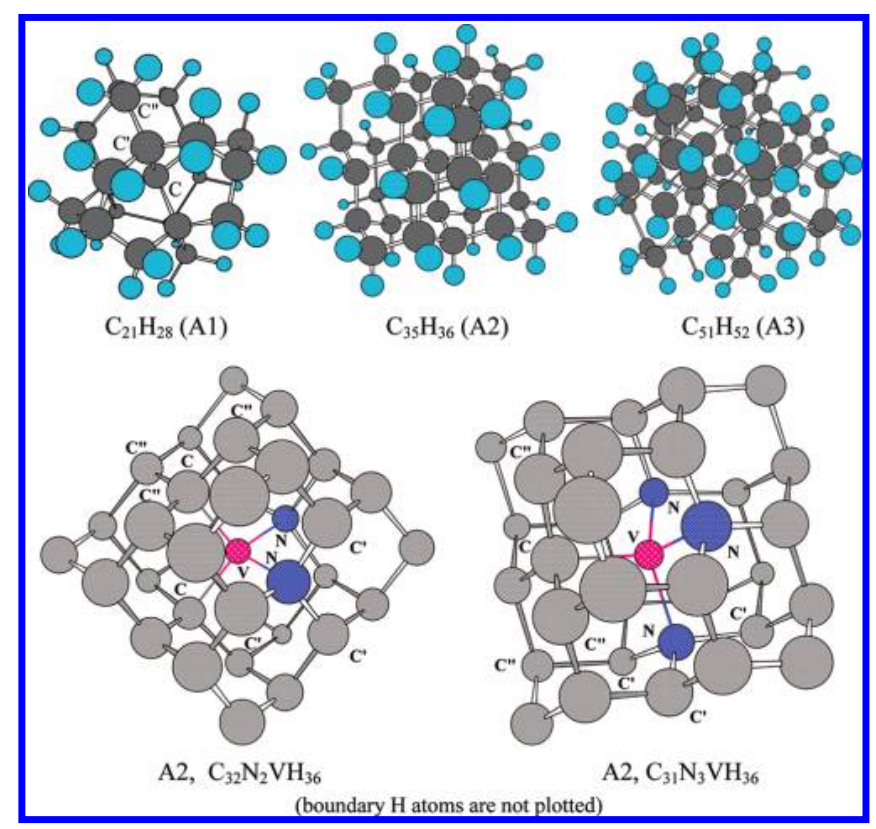

Figure 1. Model clusters used for simulations of a diamond fragment and nitrogen vacancy defects in diamond.

system. Geometry optimization of the $\mathrm{C}_{51} \mathrm{H}_{52}$ cluster was performed at the Hartree-Fock (HF) and B3LYP levels with the standard 6-31G* basis set for central 17 atoms and 6-31G for all remaining atoms. Outer $\mathrm{C}$ atoms were kept frozen in the crystalline positions, and coordinates of $\mathrm{C}$ atoms from the first and second shells and all $\mathrm{H}$ atoms were fully optimized. The same approach was used for $\mathrm{C}_{35} \mathrm{H}_{36}$, and additionally, we carried out full optimization with the $6-31 \mathrm{G}^{*}$ basis set. Geometries of smaller clusters were fully optimized at the HF, B3LYP, and MP2 levels of theory.

Geometry optimization of the model systems with vacancy and $\mathrm{N}$ atoms was performed at the B3LYP level of density functional theory with the standard $6-31+\mathrm{G}^{*}$ basis set for the central 16 atoms and 6-31G for all remaining atoms. Coordinates of the 16 atoms around vacancy were optimized, whereas positions of the other $\mathrm{C}$ and $\mathrm{H}$ atoms were kept frozen at the positions taken from the initial model systems simulating a defectless crystalline fragment. The GAUSSIAN 03 program package $^{43}$ was utilized for these calculations. In the defectless systems, the calculated $\mathrm{C}-\mathrm{C}$ bond lengths are in good agreement with the experimental values for diamond for all the models in use. However, the most accurate results were obtained at the HF and MP2 levels, with deviations from the experiment of only $\sim 0.01 \AA$; at B3LYP, the $\mathrm{C}-\mathrm{C}$ distances are slightly overestimated (Table 1). The influence of cluster size on the calculated geometric parameters appeared to be weak.

For the $\mathrm{N}_{2} \mathrm{~V}$ system, two electronic states were calculated, the neutral singlet (s) and the negatively charged doublet (d). For $\mathrm{N}_{3} \mathrm{~V}$, only the neutral doublet was considered. A schematic electronic structure for these systems is presented in Figure 2. In the $\mathrm{N}_{2} \mathrm{~V}^{0}$ system, the highest occupied molecular orbital (HOMO) corresponds to highly stretched $\mathrm{C}-\mathrm{C}$ bonds. In the $\mathrm{N}_{2} \mathrm{~V}^{-}$defect, the corresponding antibonding orbital is partially occupied, and in $\mathrm{N}_{3} \mathrm{~V}^{0}$, the unpaired electron is located at the lone pair orbital of a carbon atom neighboring the vacancy and originating from a $\mathrm{C}-\mathrm{C}$ bond broken when the vacancy is introduced. The ground-state wave functions are $1^{1} \mathrm{~A}_{1}, 1^{2} \mathrm{~B}_{1}$, and $1^{2} \mathrm{~A}_{1}$ for the $\mathrm{N}_{2} \mathrm{~V}^{0}, \mathrm{~N}_{2} \mathrm{~V}^{-}$, and $\mathrm{N}_{3} \mathrm{~V}^{0}$ defects, respectively.

Geometric changes caused by the $\mathrm{N}_{2} \mathrm{~V}$ and $\mathrm{N}_{3} \mathrm{~V}$ defects appear to be similar to those observed previously for single- 
TABLE 1: Optimized Geometric Parameters of Model Clusters without Defects ${ }^{a}$

\begin{tabular}{lcccccc}
\hline & $\begin{array}{c}\mathrm{R}_{1} \\
(\mathrm{HF})\end{array}$ & $\begin{array}{c}\mathrm{R}_{1} \\
(\mathrm{~B} 3 L Y P)\end{array}$ & $\begin{array}{c}\mathrm{R}_{1} \\
(\mathrm{MP} 2)\end{array}$ & $\begin{array}{c}\mathrm{R}_{2} \\
(\mathrm{HF})\end{array}$ & $\begin{array}{c}\mathrm{R}_{2} \\
(\mathrm{~B} 3 L Y P)\end{array}$ & $\begin{array}{c}\mathrm{R}_{2} \\
(\mathrm{MP} 2)\end{array}$ \\
\hline $\mathrm{C}_{5} \mathrm{H}_{12}{ }^{b}$ & 1.535 & 1.540 & 1.530 & - & - & - \\
$\mathrm{C}_{21} \mathrm{H}_{28}{ }^{b}$ & 1.569 & 1.576 & 1.563 & 1.564 & 1.570 & 1.560 \\
$\mathrm{C}_{35} \mathrm{H}_{36}$ & 1.557 & $1.565,1.564^{b}$ & - & 1.547 & $1.540,1.551^{b}$ & - \\
$\mathrm{C}_{51} \mathrm{H}_{52}$ & 1.548 & 1.548 & - & 1.561 & 1.563 & -
\end{tabular}

${ }^{a} \mathrm{R}_{1}$ and $\mathrm{R}_{2}$ are $\mathrm{C}-\mathrm{C}$ distances in the central fragment and in the second layer around it, respectively. The experimental $\mathrm{C}-\mathrm{C}$ distance is $1.546 \AA .{ }^{56}{ }^{b}$ Full optimization with the $6-31 G^{*}$ basis set is used, or otherwise, the $6-31 \mathrm{G}^{*}$ basis set is used for 17 central $\mathrm{C}$ atoms and 6-31G for all other atoms. Positions of 17 central atoms are optimized, and the coordinates of outer (boundary) $\mathrm{C}$ atoms are fixed in crystalline positions.

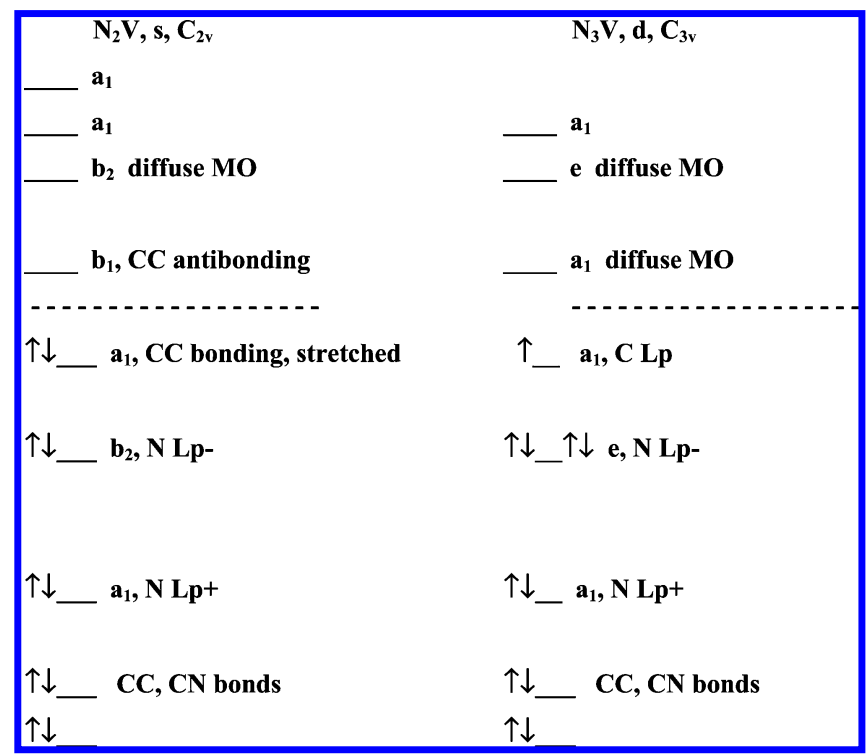

Figure 2. Schematic electronic structure of nitrogen vacancy defects.

nitrogen defects $\mathrm{NV}^{-}$and $\mathrm{NV}^{0.40,41}$ the vacancy-related atoms are shifted away from the center, whereas the variations in coordinates of the other atoms are small. The displacements are $\sim 0.1 \AA$ for the largest A3-based model systems and $\sim 0.2-0.3 \AA$ for the systems based on the A1 cluster (Table 2). Distances between bound atoms do not differ significantly for clusters of different size, and in all investigated systems, we find a trend of bond shortening between the vacancy-related atoms and their neighbors and weak changes in the opposite direction for bonds between atoms in the second and third layers. As a result, atoms from the second layer are slightly shifted toward the cluster center, but these displacements are very small.

The distance between the vacancy-related $\mathrm{C}$ atoms in the $\mathrm{N}_{2} \mathrm{~V}$ defect is the shortest for the singlet state but is longer in $\mathrm{N}_{2} \mathrm{~V}^{-}$(d), in accordance with the character of the boundary orbitals. In the singlet state, the weak $\mathrm{C}-\mathrm{C}$-bonding $\mathrm{HOMO}$ is doubly occupied, whereas in the negatively charged doublet state, an electron is accepted to the antibonding MO (Figure 2). Mulliken spin distributions and isotropic Fermi contact couplings at the ${ }^{14} \mathrm{~N}$ and ${ }^{13} \mathrm{C}$ nuclei used as a measure of the spin distribution in open shell systems indicate that the unpaired electron is located at the vacancy-related $\mathrm{C}$ atoms (Table 3). The nitrogen-related electron distribution is weakly polarized, at least in the ground states of these systems.

Before starting calculations of excited electronic states, we tested the ability of various theoretical methods and basis sets to simulate the forbidden energy gap in diamond using our model clusters. The forbidden gap was estimated as the energy of the $\mathrm{S}_{0}-\mathrm{S}_{1}$ transition in defectless $\mathrm{C}_{21} \mathrm{H}_{28}$ and $\mathrm{C}_{35} \mathrm{H}_{36}$ clusters, which was calculated using the time-dependent density functional (TD-B3LYP), outer valence Green's function (OVGF), ${ }^{44,45}$ and HF methods. The latter was used only for fast estimations of the exponent values for diffuse basis functions suitable for simulating the conducting zone. It is important to remember that estimation of the forbidden gap width as the HOMO-LUMO difference is valid only for methods that neglect electron repulsion (such as Hückel's approach). Within the HF method, the transition energy was calculated in the same manner as in OVGF but without the relaxation and correlation corrections, i.e., by taking the difference of electron affinities for the positively charged system within the Koopmans theorem. ${ }^{45}$ At the HF level with the $6-31+G^{*}$ basis set, the $S_{0}-S_{1}$ excitation energy for the $\mathrm{C}_{21} \mathrm{H}_{28}$ cluster was evaluated as $6.9 \mathrm{eV}$, which is significantly higher compared to that of the experimental gap width for diamond, $5.5 \mathrm{eV}$. Extension of the basis set by adding a diffuse sp-shell leads to a decrease of the excitation energy, and with the optimal exponent value of 0.01 for the diffuse functions (which ensured that the excitation energies for the first four transitions in this model system achieved lowest values), it was reduced by $\sim 1.5 \mathrm{eV}$. The alteration of this parameter in the range of $0.005-0.015$ results in very small changes of the excitation energy, within $\sim 0.01-0.02 \mathrm{eV}$. With this new basis set, $6-31+G^{*}+\operatorname{sp}(0.01)$, the $S_{0}-S_{1}$ transition energy for the $\mathrm{C}_{21} \mathrm{H}_{28}$ cluster was calculated to be 6.1 and 5.8 $\mathrm{eV}$ at the OVGF and TD-B3LYP levels, respectively. For the larger $\mathrm{C}_{35} \mathrm{H}_{36}$ system, this value is slightly lower, $5.5 \mathrm{eV}$ at the TD-B3LYP level. We therefore conclude that to properly describe electronic states near the conductive zone, the basis set should be augmented by $\mathrm{sp}$ diffuse functions with the exponent of $\sim 0.01$. For the $\mathrm{N}_{2} \mathrm{~V}^{0}$ system, this value was refined by $\mathrm{CASSCF}^{46,47}$ and OVGF calculations for the lowest Rydbertype states. The optimized exponents were found to be $\sim 0.015$ for the vacancy-related atoms and $\sim 0.01$ for the atoms from the next layer around the vacancy, and the basis set, including these diffuse functions, is designated as B5.

Excited States. A. TD-DFT and CCSD Results. At the initial stage, excitation energies were calculated using the computationally fastest TD-B3LYP approach with different basis sets and model clusters. Because the coordinates of the vacancyrelated atoms somewhat differ in clusters of various sizes, two types of the ground-state geometries were utilized, with the coordinates taken from the largest A3-based clusters (case a) and with those optimized for the used model system (case b). This results in moderate variations of the calculated excitation energies, within $0.2-0.3 \mathrm{eV}$. A change of the cluster size causes a smaller alteration of the lowest excitation energy, of $\sim 0.1$ $\mathrm{eV}$, however, for higher transitions the variations are sometimes more substantial (see Table 4).

In the $\mathrm{N}_{2} \mathrm{~V}^{0}$ system, the first excitation corresponds to the electronic transition from the stretched $\mathrm{C}-\mathrm{C}$ bond ( $\mathrm{a}_{1}$ orbital) to the antibonding $b_{1} \mathrm{MO}$ (see Figure 2). The corresponding oscillator strength is significant. The next excitation proceeds from $b_{2}$ (an antibonding combination of nitrogen lone pairs) to $\mathrm{b}_{1} \mathrm{MO}$ and is symmetry forbidden. Several subsequent excited states are formed with participation of diffuse orbitals split from the conductive zone into the forbidden gap in the defect region. The energies of these states are very sensitive to the inclusion of diffuse functions into the basis set, whereas their effect on the first two transitions is rather small (Table 4). So as the experimental PA band for this defect is peaked at $2.58 \mathrm{eV},{ }^{2}$ the excitation energy for the $1^{1} \mathrm{~B}_{1} \leftarrow 1^{1} \mathrm{~A}_{1}$ transition calculated at 
TABLE 2: Interatomic Distances $\mathbf{R}(\mathrm{AB})$ for Model Clusters with NV Defects in Different Electronic States ${ }^{a}$

\begin{tabular}{cccccccc}
\hline system & $\mathrm{R}(\mathrm{CC})(\AA)$ & $\mathrm{R}(\mathrm{VN})(\AA)$ & $\mathrm{R}(\mathrm{VC})(\AA)$ & $\mathrm{R}(\mathrm{NC})(\AA)$ & $\mathrm{R}\left(\mathrm{CC}^{\prime \prime}\right)(\AA)$ & $\mathrm{R}\left(\mathrm{VC}^{\prime}\right)(\AA)$ & $\mathrm{R}\left(\mathrm{VC}^{\prime \prime}\right)(\AA)$ \\
\hline $\mathrm{A} 1, \mathrm{~N}_{3} \mathrm{~V}^{0}, \mathrm{~d}$ & - & 1.82 & 1.84 & 1.48 & 1.48 & 2.54 & 2.55 \\
$\mathrm{~A} 1, \mathrm{~N}_{2} \mathrm{~V}^{0}, \mathrm{~s}$ & 2.82 & 1.85 & 1.75 & 1.47 & $1.50,1.54$ & 2.54 & $2.53,2.55$ \\
$\mathrm{~A} 1, \mathrm{~N}_{2} \mathrm{~V}^{-}, \mathrm{d}$ & 2.92 & 1.85 & 1.80 & $1.47,1.48$ & $1.49,1.50$ & 2.54 & $2.53,2.54$ \\
$\mathrm{~A} 2, \mathrm{~N}_{3} \mathrm{~V}^{0}, \mathrm{~d}$ & - & 1.68 & 1.73 & $1.48,1.49$ & 1.50 & 2.51 & 2.52 \\
$\mathrm{~A} 2, \mathrm{~N}_{2} \mathrm{~V}^{0}, \mathrm{~s}$ & 2.66 & 1.69 & 1.67 & 1.48 & $1.49,1.54$ & 2.52 & $2.49,2.52$ \\
$\mathrm{~A} 2, \mathrm{~N}_{2} \mathrm{~V}^{-}, \mathrm{d}$ & 2.72 & 1.70 & 1.68 & 1.48 & $1.49,1.50$ & 2.51 \\
$\mathrm{~A} 3, \mathrm{~N}_{3} \mathrm{~V}^{0}, \mathrm{~d}$ & - & $1.63,1.64$ & 1.67 & $1.51,1.52$ & 1.52 & $2.52,2.54$ \\
$\mathrm{~A} 3, \mathrm{~N}_{2} \mathrm{~V}^{0}, \mathrm{~s}$ & 2.49 & 1.65 & 1.59 & 1.51 & $1.51,1.59$ & 2.53 & 2.53 \\
$\mathrm{~A} 3, \mathrm{~N}_{2} \mathrm{~V}^{-}, \mathrm{d}$ & 2.59 & 1.65 & 1.61 & $1.50,1.51$ & $1.52,1.54$ & 2.53 & $2.59,2.54$
\end{tabular}

${ }^{a}$ Geometric parameters are optimized at the B3LYP level with the 6-31+ $\mathrm{G}^{*}$ basis set for central atoms $1-16$ and 6-31G for all other atoms. Parent defectless clusters are $\mathrm{C}_{21} \mathrm{H}_{28}$ for $\mathrm{A} 1, \mathrm{C}_{35} \mathrm{H}_{36}$ for $\mathrm{A} 2$, and $\mathrm{C}_{51} \mathrm{H}_{52}$ for $\mathrm{A} 3$. $\mathrm{N}$ and $\mathrm{C}$ are atoms around the vacancy $(\mathrm{V})$, and $\mathrm{C}^{\prime}$ and $\mathrm{C}^{\prime \prime}$ are atoms from the next layer connected with $\mathrm{N}$ and $\mathrm{C}$, respectively.

TABLE 3: Calculated Spin Densities (SD) and Isotropic Fermi Contact Couplings (IFCC) at the $\mathrm{N}^{14}$ and $\mathrm{C}^{13} \mathrm{Nuclei}^{\mathrm{in}} \mathrm{Model}$ Clusters $^{a}$

\begin{tabular}{ccccc}
\hline system & N SD, IFCC $\left(10^{-4} \mathrm{~cm}^{-1}\right)$ & $\mathrm{C} \mathrm{SD}$, IFCC $\left(10^{-4} \mathrm{~cm}^{-1}\right)$ & $\mathrm{C}^{\prime}$ (N-bonded) SD, IFCC $\left(10^{-4} \mathrm{~cm}^{-1}\right)$ & $\mathrm{C}^{\prime \prime}\left(\mathrm{C}\right.$-bonded) SD, IFCC $\left(10^{-4} \mathrm{~cm}^{-1}\right)$ \\
\hline $\mathrm{A} 1, \mathrm{~N}_{2} \mathrm{~V}^{-}$, d & $0.06,-0.1$ & $0.22,36.1$ & 0.00 to $-0.02,-1.3$ to 0.4 & -0.03 to $0.07,-3.3$ to -7.4 \\
$\mathrm{~A} 1, \mathrm{~N}_{3} \mathrm{~V}^{0}, \mathrm{~d}$ & $0.02,0.6$ & $0.71,56.5$ & $0.00,-0.8$ to 0.2 & $-0.01,-9.3$ \\
$\mathrm{~A} 2, \mathrm{~N}_{2} \mathrm{~V}^{-}, \mathrm{d}$ & $0.10,-0.2$ & $-0.11,56.4$ & -0.02 to $-0.04,-0.4$ to 0.2 & -0.01 to $0.24,-0.5$ to -4.3 \\
$\mathrm{~A} 2, \mathrm{~N}_{3} \mathrm{~V}^{0}, \mathrm{~d}$ & $0.03,2.1$ & $0.46,79.0$ & -0.01 to $0.00,-0.5$ to 0.6 & $0.07,-6.3$ \\
$\mathrm{~A} 3, \mathrm{~N}_{2} \mathrm{~V}^{-}, \mathrm{d}$ & -0.06 & 0.35 & 0.04 to 0.08 & -0.03 to 0.04 \\
$\mathrm{~A} 3, \mathrm{~N}_{3} \mathrm{~V}^{0}, \mathrm{~d}$ & 0.06 & 0.48 & -0.02 to 0.00 & 0.09
\end{tabular}

${ }^{a} \mathrm{~N}_{2} \mathrm{~V}^{-}$and $\mathrm{N}_{3} \mathrm{~V}$ defects are calculated at the B3LYP level with the 6-31+G* basis set for central atoms 1-16 and 6-31G for all other atoms. Parent defectless clusters are $\mathrm{C}_{21} \mathrm{H}_{28}$ for $\mathrm{A} 1, \mathrm{C}_{35} \mathrm{H}_{36}$ for $\mathrm{A} 2$, and $\mathrm{C}_{51} \mathrm{H}_{52}$ for $\mathrm{A} 3 . \mathrm{N}$ and $\mathrm{C}$ are atoms around the vacancy, and $\mathrm{C}^{\prime}$ and $\mathrm{C}^{\prime \prime}$ are atoms from the next layer connected with $\mathrm{N}$ and $\mathrm{C}$, respectively.

the TD-DFT level is significantly underestimated $(\sim 0.5 \mathrm{eV})$. Calculations using the CIS(D) approach result in very high energies for the first excitation. The more sophisticated EOMCCSD method ${ }^{47}$ gives more realistic transition energies, $0.4-0.7$ $\mathrm{eV}$ higher than the experimental values. Investigation of the basis set dependence shows that the inclusion of diffuse functions for the vacancy-related atoms is essential for the energy of the $1^{1} \mathrm{~B}_{1} \leftarrow 1^{1} \mathrm{~A}_{1}$ transition, but there is no perceptible difference between the functions with exponents of 0.015 and 0.010. Further extension of the basis set by adding diffuse functions at the atoms from the second shell has only a weak effect on the energies of the two lowest excitations but causes an energy decrease for the higher Rydberg-like (diffuse) $2^{1} \mathrm{~A}_{1}$ and $1^{1} \mathrm{~B}_{2}$ states (Table 5). The use of geometric parameters from the largest model cluster leads to an increase in the excitation energies of $0.2-0.3 \mathrm{eV}$ for the $1^{1} \mathrm{~B}_{1}$ and $1^{1} \mathrm{~A}_{2}$ valence states and of $0.1-0.2 \mathrm{eV}$ for the $2^{1} \mathrm{~A}_{1}$ and $1^{1} \mathrm{~B}_{2}$ diffuse states. Finally, with the best basis set and geometric parameters, the EOMCCSD energy for the vertical $1{ }^{1} \mathrm{~B}_{1} \leftarrow 1^{1} \mathrm{~A}_{1}$ transition calculated with the A1-a model cluster overestimates the experimental value by $\sim 0.6 \mathrm{eV}$. As will be discussed later, the reason for this poor performance by EOM-CCSD is a multireference character of the states considered.

For the negatively charged doublet $\mathrm{N}_{2} \mathrm{~V}^{-}$, the first excited state is formed by electronic transition from the stretched $\mathrm{C}-\mathrm{C}$ bond $\left(a_{1}\right)$ to the antibonding $b_{1} \mathrm{MO}$. The resulting $1^{2} \mathrm{~A}_{1}$ state has the doubly occupied $b_{1}$ orbital and a hole at the lower $a_{1}$ MO. Several subsequent states are formed by electronic transitions from the highest $b_{1}$ or $a_{1}$ MOs to diffuse orbitals. The calculated excitation energies of these states are underestimated at the TD-DFT level. One can expect that this underestimation should be more significant for the states involving diffuse orbitals due to the well-known erroneous description of the asymptotic behavior of the electron from the most common density functionals. ${ }^{48-51}$

In the $\mathrm{N}_{3} \mathrm{~V}^{0}$ system, the first excited state is degenerate $\left(1^{2} \mathrm{E}\right.$ split to $2^{2} \mathrm{~A}^{\prime}$ and $1^{2} \mathrm{~A}^{\prime \prime}$ components, if symmetry is lowered from
$\mathrm{C}_{3 \mathrm{v}}$ to $\mathrm{C}_{\mathrm{s}}$ ). It is formed by electronic transition from the antibonding combinations formed by lone pairs of the nitrogen atoms (Figure 2) to the singly occupied $\mathrm{a}_{1} \mathrm{MO}$, a lone pair of the $\mathrm{C}$ atom adjacent to the vacancy. The corresponding energy appears to not be very sensitive to the basis set extension, variations of geometric parameters, and cluster size (Table 4). The calculated excitation energy is rather close to the experimental PA band maximum, about $3 \mathrm{eV}$, but the computed oscillator strength is too small. The next state, $3^{2} \mathrm{~A}^{\prime}$ in $\mathrm{C}_{\mathrm{s}}$ or $2^{2} \mathrm{~A}_{1}$ in $\mathrm{C}_{3 \mathrm{v}}$, is formed by electronic transfer from the dangling bond of the 3-fold coordinated $\mathrm{C}$ atom to the lowest diffuse orbital; this is the HOMO-LUMO transition in the $\alpha$-spin subsystem. The calculated oscillator strength for this excitation is significant, and so it is probable that the observed PA band for the $\mathrm{N}_{3} \mathrm{~V}^{0}$ defect corresponds to this transition. However, the theoretical value of the excitation energy for this state is sensitive to the basis set quality and model cluster geometry and size; at some levels of theory, the $2^{2} \mathrm{~A}_{1}$ state exhibits a slightly lower energy than $1^{2} \mathrm{E}$ (Table 4). Additionally, the TD-DFT approach, as a rule, substantially underestimates excitation energies for diffuse states, and the results need to be refined using more sophisticated and reliable methods. Therefore, we applied the multireference perturbation theory CASPT2 approach ${ }^{52,53}$ henceforth.

B. CASPT2 Results. The systems under consideration appeared to require special care when they were calculated using the CASPT2 method. Difficulties arise from the CASSCF stage, which generates initial wave functions needed for the further perturbation theory treatment and often gives excited states in an incorrect order. For instance, several diffuse states computed at the CASSCF level have lower energies than those of the valence excited states but a more complete account of electronic correlation such as the inclusion of dynamic correlation in CASPT2 reverses their order. Extension of the active space by including vacant MOs or addition of diffuse functions to the basis set increases the amount of such diffuse states intermingling with valence states. As a result, electronic states with lower 
TABLE 4: Vertical Excitation Energies (eV, First Values) and Oscillator Strengths (Second Values) Calculated at the TD-B3LYP and CIS(D) Levels of Theory for the $N_{2} V$ and $N_{3} V$ Defects in Various Model Clusters ${ }^{a}$

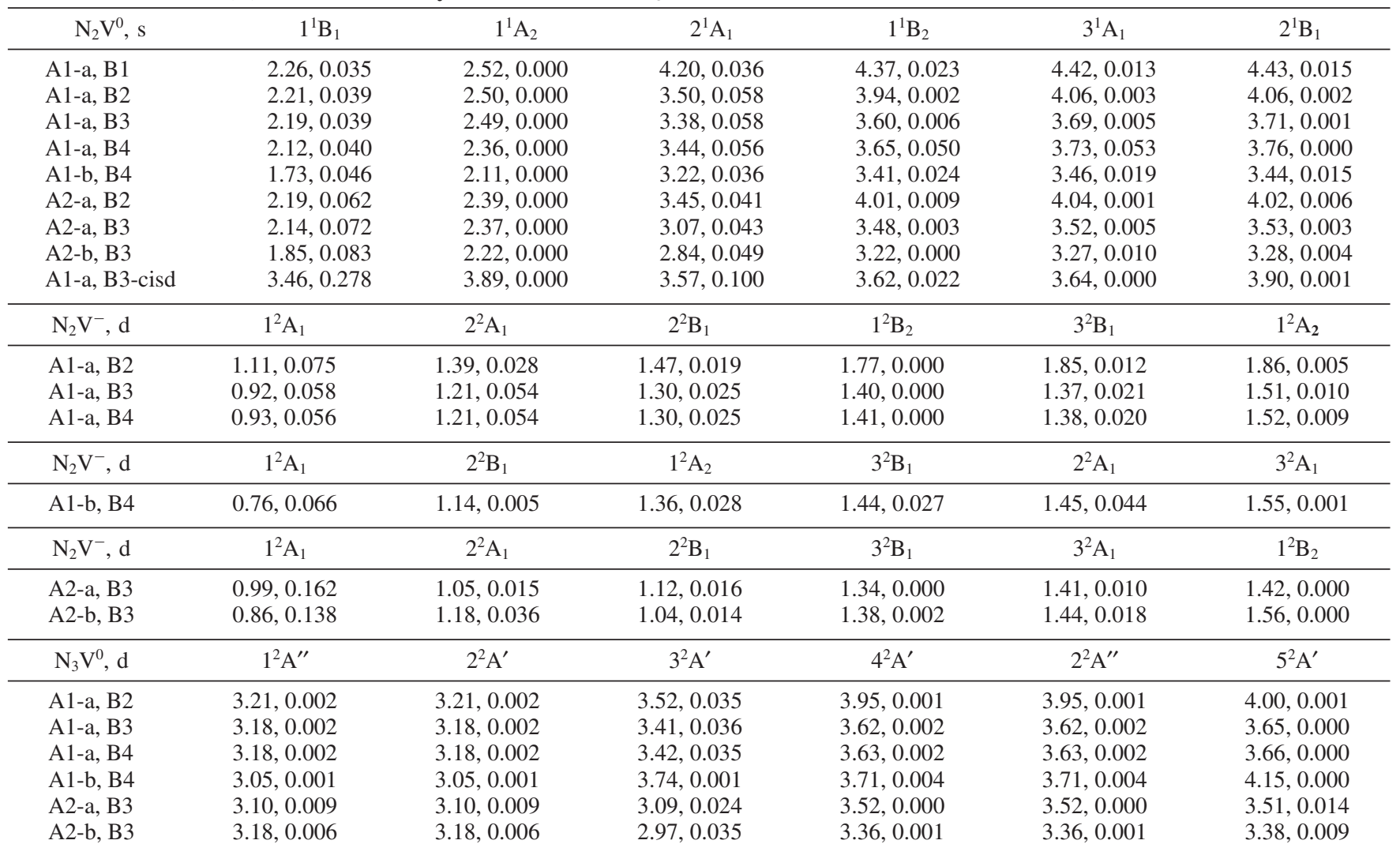

${ }^{a}$ Basis set notation is the following. B1: $6-31+\mathrm{G}^{*}$ for vacancy-related atoms, $6-31 \mathrm{G}^{*}$ for atoms from the next layer, and $6-31 \mathrm{G}$ at all other atoms. B2: B1 $+\mathrm{s}(0.0438)$ for atoms from the second layer. B3: 6-31+ $\mathrm{G}^{*}$ for atoms from the first and second layers around the vacancy and 6-31G for all other atoms. B4: 6-311+G* for vacancy-related atoms, 6-31+G* for atoms from the next layer, and 6-31G for all other atoms. In the designation of model clusters, "a" indicates that coordinates of vacancy-related atoms were taken from the A3 cluster, and "b" indicates that these parameters were optimized for the cluster used.

TABLE 5: Vertical Excitation Energies (eV) Calculated at the EOM-CCSD Level with Various Basis Sets for the $\mathrm{N}_{2} \mathbf{V}^{0}$ Defect using the A1-b Model Cluster

\begin{tabular}{|c|c|c|c|c|c|}
\hline \multicolumn{2}{|c|}{ basis sets } & \multicolumn{4}{|c|}{ electronic states } \\
\hline atoms $\mathrm{N}$ and $\mathrm{C}$ & atoms $\mathrm{C}^{\prime}$ and $\mathrm{C}^{\prime \prime}$ & $1{ }^{1} \mathrm{~B}_{1}$ & $1^{1} \mathrm{~A}_{2}$ & $2^{1} \mathrm{~A}_{1}$ & $1^{1} \mathrm{~B}_{2}$ \\
\hline PVDZ & $6-31 G^{*}$ & 3.28 & 3.44 & 5.72 & 6.49 \\
\hline PVTZ & $6-31 G^{*}$ & 3.24 & 3.44 & 5.78 & 6.55 \\
\hline APVDZ & $6-31 G^{*}$ & 3.14 & - & 4.40 & - \\
\hline APVTZ & $6-31 \mathrm{G}^{*}$ & 3.09 & 3.33 & 4.21 & 4.52 \\
\hline $6-31+\mathrm{G}^{*}$ & $6-31 \mathrm{G}^{*} ; 0.0438 \mathrm{~s}$ & 3.13 & 3.35 & 4.06 & 4.46 \\
\hline${ }^{a} 6-31+\mathrm{G}^{*}$ & $6-31 \mathrm{G}^{*} ; 0.0438 \mathrm{~s}$ & 3.39 & 3.66 & 4.18 & 4.58 \\
\hline APVDZ & $6-31 \mathrm{G}^{*} ; 0.01 \mathrm{~s}$ & 3.00 & - & 3.29 & 3.50 \\
\hline APVTZ & $6-31 \mathrm{G}^{*} ; 0.01 \mathrm{~s}$ & 3.00 & 3.30 & 3.35 & 3.57 \\
\hline APVDZ; 0.015 sp & $6-31 G^{*}$ & 2.97 & - & 3.33 & 3.55 \\
\hline APVTZ; 0.015 sp & $6-31 G^{*}$ & 2.98 & 3.28 & 3.38 & 3.61 \\
\hline APVDZ; 0.015 sp & $6-31 \mathrm{G}^{*} ; 0.01 \mathrm{~s}$ & 2.97 & 3.27 & 3.29 & 3.51 \\
\hline APVDZ; $0.010 \mathrm{sp}$ & $6-31 \mathrm{G}^{*} ; 0.01 \mathrm{~s}$ & 2.95 & 3.26 & 3.17 & 3.40 \\
\hline APVTZ; $0.015 \mathrm{sp}$ & $6-31 \mathrm{G}^{*} ; 0.01 \mathrm{~s}$ & 2.98 & 3.28 & 3.34 & 3.57 \\
\hline${ }^{a}$ APVDZ; $0.010 \mathrm{sp}$ & $6-31 \mathrm{G}^{*} ; 0.01 \mathrm{~s}$ & 3.18 & 3.59 & 3.34 & 3.57 \\
\hline${ }^{a} \mathrm{APVDZ} ; 0.015 \mathrm{sp}$ & $6-31 \mathrm{G}^{*} ; 0.01 \mathrm{~s}$ & 3.17 & 3.58 & 3.35 & 3.58 \\
\hline
\end{tabular}

energies, according to the more accurate CASPT2 approach, in many cases correspond to high-lying states at the CASSCF level and may not be present among the available CASCCF roots. Because of this, important low-lying valence states can be overlooked if the CASPT2/CASSCF calculation scheme is applied in a straightforward manner. To circumvent this problem and to select a suitable approach, we tested a variety of combinations of active spaces with different numbers of calculated roots. The use of a high number of roots results in poor convergence at the perturbation theory stage, and therefore, a level shift with parameters of 0.3 and 0.4 au was applied. ${ }^{52,53}$ The presented results correspond to the shift value of 0.3 . So as no obvious internal criteria of the quality of calculations are available within the CASPT2 approach, we selected the results with the lowest ground-state energy and smallest values of derivatives of excitation energies with respect to the shift value $(\mathrm{d} E / \mathrm{d} s)$. Combinations giving a substantial increase of the ground-state energy and high $\mathrm{d} E / \mathrm{d} s$ values were regarded as unsuccessful. The best results obtained are collected in Table 6 , and more detailed information can be found in Table 7. Normally, a large number of roots were required because rather high CASSCF states exhibited significant contributions in the lowest CASPT2 states. For example, for the $\mathrm{N}_{2} \mathrm{~V}^{0}$ system with the $(16,11)$ active space, up to 12 CASSCF states substantially contributed to the low-lying $2^{1} \mathrm{~A}_{1}$ and $1^{1} \mathrm{~B}_{1}$ CASPT2 states. Nevertheless, the behavior of the results was not always monotonous, and the state energy oscillated with an increase in the number of calculated roots.

For the valence $1^{1} \mathrm{~B}_{1}$ state of the $\mathrm{N}_{2} \mathrm{~V}^{0}$ defect, reasonable results can be obtained with a minimal $(8,5)$ active space, which includes a single unoccupied orbital of either $a_{1}$ or $b_{1}$ symmetry. Extension of the active space does not substantially change the corresponding excitation energy. The diffuse $2^{1} \mathrm{~A}_{1}$ state appears to be more sensitive to the active space size; when it is extended by inclusion of empty MOs, the excitation energy of this state significantly decreases (Table 6). As in the preliminary TD- 
TABLE 6: Vertical Excitation Energies of NV Defects Calculated at the CASPT2 Level ${ }^{a}$

\begin{tabular}{|c|c|c|c|c|}
\hline $\begin{array}{c}\text { model system } \\
\text { basis set }\end{array}$ & \multirow[b]{2}{*}{$\mathrm{Ne} / \mathrm{No},{ }^{b} \mathrm{RN}^{c}$} & $\begin{array}{c}-E_{\mathrm{t}}(\mathrm{GS})^{d} \\
(\mathrm{au})\end{array}$ & $\begin{array}{c}E_{\mathrm{r}}(1), \mathrm{d} E / \mathrm{d} s^{e} \\
(\mathrm{eV})\end{array}$ & $\begin{array}{c}\begin{array}{c}E_{\mathrm{r}}(2), \mathrm{d} E / \mathrm{d} s^{e} \\
(\mathrm{eV})\end{array}\end{array}$ \\
\hline $\mathrm{N}_{2} \mathrm{~V}^{0}$ & & $1^{1} \mathrm{~A}_{1}$ & $1^{1} \mathrm{~B}_{1}$ & $2^{1} \mathrm{~A}_{1}$ \\
\hline A1-b, B5 & $8 / 5(2,2,1,0), 4$ & 809.19683 & $2.47,0.02$ & $3.31,0.02$ \\
\hline A1-b, B5 & $12 / 7(2,2,2,1), 6$ & 809.19803 & $2.46,0.02$ & $3.21,0.02$ \\
\hline A1-b, B5 & $16 / 9(3,3,2,1), 8$ & 809.19789 & $2.46,0.02$ & $3.11,0.02$ \\
\hline A1-a, B5 & $12 / 7(2,2,2,1), 6$ & 809.16391 & $2.63,0.02$ & $3.83,0.02$ \\
\hline A1-a, B5 & $16 / 9(3,3,2,1), 8$ & 809.16463 & $2.63,0.02$ & $3.62,0.03$ \\
\hline A1-a, B5 & $16 / 11(4,4,2,1), 21$ & 1809.16704 & $2.62,0.04$ & $3.37,0.10$ \\
\hline A1-a, B5 & $16 / 13(4,4,3,2), 19$ & 809.16518 & $2.49,0.07$ & $3.35,0.11$ \\
\hline A1-a, B4a & $12 / 7(2,2,2,1), 6$ & 809.16269 & $2.63,0.01$ & $3.83,0.02$ \\
\hline A1-a, B4a & $16 / 11(4,4,2,1), 19$ & 809.16596 & $2.62,0.04$ & $3.36,0.10$ \\
\hline A1-a, B4a & $16 / 11(4,4,2,1), 21$ & 1809.16606 & $2.63,0.04$ & $3.36,0.10$ \\
\hline Expt. & & & $\begin{array}{l}2.58, f 2.33, g \\
2.46^{h}\end{array}$ & $3.4^{I}$ \\
\hline $\mathrm{N}_{2} \mathrm{~V}^{-}$ & $\mathrm{Ne} / \mathrm{No},{ }^{b} \mathrm{RN}$ & $1^{2} \mathrm{~B}_{1}$ & $1^{2} \mathrm{~A}_{1}$ & $2^{2} \mathrm{~B}_{1}$ \\
\hline A1-a, B4a & 16/11 (4,4,2,1), 21 & 809.15243 & $0.12,0.02$ & $0.51,0.01$ \\
\hline $\mathrm{A} 1-\mathrm{a}, \mathrm{B} 4 \mathrm{a}$ & $11 / 11(3,6,1,1), 25$ & 809.16907 & $0.93,-0.16$ & $1.06,-0.14$ \\
\hline A1-a, B4a & $11 / 12(3,7,1,1), 27$ & 809.17107 & $0.96,-0.17$ & $1.11,-0.15$ \\
\hline A1-a, B3a & $11 / 11(3,6,1,1), 21$ & 809.16163 & $1.54,-0.01$ & $2.48,-0.09$ \\
\hline Expt. & & & $1.26^{h}$ & \\
\hline $\mathrm{N}_{3} \mathrm{~V}^{0}$ & $\mathrm{Ne} / \mathrm{No},{ }^{b} \mathrm{RN}$ & $1^{2} \mathrm{~A}_{1}$ & $1^{2} \mathrm{E}$ & $1^{2} \mathrm{~A}_{1}$ \\
\hline $\begin{array}{l}\text { A1-a, B5 } \\
\text { Expt. }\end{array}$ & $3 / 12(7,5), 21$ & 825.79632 & $\begin{array}{l}3.07,0.06 \\
3.0^{f} 28^{g}\end{array}$ & $3.31,0.02$ \\
\hline
\end{tabular}

${ }^{a}$ Basis set notation is the following. B5: aug-cc-pVDZ + diffuse sp functions $(0.015)$ for vacancy-related atoms, 6-31G* $+\mathrm{s}(0.010)$ for atoms from the second layer, and 6-31G for all other atoms. B4a: B5 without diffuse s (0.010) functions for atoms from the second layer. B3a: B4a without sp (0.015) for vacancy-related atoms. ${ }^{b} \mathrm{Ne} / \mathrm{No}$ are numbers of active electrons and active orbitals In parentheses, the number of active orbitals are given for each irreducible representation, $A_{1}, B_{1}, B_{2}$, and $A_{2}$, within $C_{2 v}$ symmetry for the $\mathrm{N}_{2} \mathrm{~V}^{0}$ and $\mathrm{N}_{2} \mathrm{~V}^{-}$defects, and $\mathrm{A}^{\prime}$ and $\mathrm{A}^{\prime \prime}$ within $\mathrm{C}_{\mathrm{s}}$ symmetry for $\mathrm{N}_{3} \mathrm{~V}^{0}$. ${ }^{c} \mathrm{RN}$ is the number of calculated roots. ${ }^{d} E_{\mathrm{t}}$ is a total energy of the ground state. ${ }^{e} E_{\mathrm{r}}$ is the relative energy of an excited state $(\mathrm{eV})$, and $\mathrm{d} E / \mathrm{d} s$ denotes derivatives of excitation energy with respect to shift value. ${ }^{f}$ Photoabsorption band maximum from ref 2 . ${ }^{g}$ Zero phonon line from ref $2 .{ }^{h}$ Zero phonon line from ref 27. ${ }^{I}$ Several nonluminescent lines (so-called H13 system). ${ }^{27}$

DFT and EOM-CCSD calculations, the use of a larger and more rigid cluster (A1-a model) results in higher calculated excitation energies. Finally, with the same A1-a model cluster, the vertical excitation energy calculated at the CASPT2 level for the $1^{1} \mathrm{~B}_{1}$ state is in good agreement with the observed PA band maximum for $\mathrm{N}_{2} \mathrm{~V}^{0}$. It is worth noting that removal of the diffuse basis functions from atoms in the second layer around the vacancy (B5 and B4a sets in Table 6) does not change the lowest excitation energies.

The wave functions for different states of this system are rather complicated, so the resulting CASPT2 states in many cases are constructed from a mixture of the available CASSCF roots. Only for the $1^{1} \mathrm{~A}_{1}$ ground state does a single root have a deciding contribution in the resulting CASPT2 wave function, but it contains two determinants with coefficients having absolute values above 0.1, $0.96(2220 / 2200 / 220 / 20)-0.22$ (2200/2220/220/20). In these notations and below, 2 and 0 stand for closed shell and empty active orbitals, respectively, and "u" and "d" designate singly occupied orbitals with spins up and down. The orbitals in the active space are ordered within each irreducible representation of the symmetry group; for example, the (2220/2200/220/20) configuration for a $C_{2 v}$ symmetric cluster used for calculations of the $\mathrm{N}_{2} \mathrm{~V}^{0}$ defect corresponds to three doubly occupied $\mathrm{a}_{1}$, two $\mathrm{b}_{1}$, two $\mathrm{b}_{2}$, and one $\mathrm{a}_{2}$ orbitals. Thus, one can see that the $1^{1} \mathrm{~A}_{1} \mathrm{CASPT} 2$ wave function consists of a dominant reference plus a determinant produced by an $\mathrm{a}_{1}{ }^{2} \rightarrow \mathrm{b}_{1}{ }^{2}$ double excitation.

The excited $2^{1} \mathrm{~A}_{1}$ state at the CASPT2 stage involves seven CASSCF roots with substantial contributions, but the resulting CASPT2 wave function is mainly two-determinant, 0.92 (2200/ $2220 / 220 / 20)+0.26(2220 / 2200 / 220 / 20)$. So, the $2^{1} \mathrm{~A}_{1}$ state is essentially the orthogonal complement to the $1^{1} \mathrm{~A}_{1}$ wave function, with the leading determinant corresponding to the $a_{1}{ }^{2} \rightarrow b_{1}{ }^{2}$ double excitation. For the lowest excited $1^{1} B_{1}$ state, four CASSCF roots contribute to the CASPT2 wave function, but finally, it includes two main determinants, $0.86(22 \mathrm{u} 0 / 22 \mathrm{~d} 0 /$ $220 / 20)+0.47(2 \mathrm{u} 20 / 22 \mathrm{~d} 0 / 220 / 20)$. Apparently, the essentially two-determinant character of the $1^{1} \mathrm{~B}_{1}$ state is the main reason why the energy of this state is overestimated at the EOM-CCSD level. According to this consideration, the first excitation in the $\mathrm{N}_{2} \mathrm{~V}^{0}$ defect is formed by electronic transfer from the stretched $\mathrm{C}-\mathrm{C}$ bond ( $\left.\mathrm{a}_{1} \mathrm{HOMO}\right)$ to the antibonding CC MO ( $\mathrm{b}_{1}$ LUMO), but the combination of nitrogen lone pairs ( $\mathrm{a}_{1}$ HOMO-2) also contributes.

As was discussed earlier, the first electronic excitation in the negatively charged $\mathrm{N}_{2} \mathrm{~V}^{-}$defect has a similar character to that in the neutral system, with the main contribution given by an electron transfer from the stretched $\mathrm{C}-\mathrm{C}$ bond $\left(\mathrm{a}_{1}\right)$ to the antibonding $\mathrm{b}_{1} \mathrm{MO}$. Unfortunately, in this case the CASPT2 method appears to be much less suitable, so HF and CASSCF calculations failed to generate acceptable initial wave functions for this cluster. Within both methods, the negative $\mathrm{N}_{2} \mathrm{~V}^{-}$defect is less stable than the neutral one, and the extra charge is spread on the periphery of the model system. For this reason, the calculation of the $\mathrm{N}_{2} \mathrm{~V}^{-}$system with the active space, which was found to be the best for the neutral $\mathrm{N}_{2} \mathrm{~V}^{0}$ defect, gives a higher total energy for the ground state of $\mathrm{N}_{2} \mathrm{~V}^{-}$as compared to that of $\mathrm{N}_{2} \mathrm{~V}^{0}$ (Table 6). Essentially, at this level of theory, the $\mathrm{N}_{2} \mathrm{~V}^{0}$ defect is unable to hold an extra electron. To improve the results at the PT2 step, one has to use a rather large active space extended by including empty MOs and computing a large number of roots, which is limited by computational facilities and by poor convergence. Even with the largest B5 basis set, we were unable to obtain a correct description of the ground state; the calculated energies were higher than that for the ground state of the neutral defect with all tested combinations of the active space and number of roots. To some extent, this is similar to a so-called variational collapse of CI calculations for a negative ion, where the extra electron is artificially placed at a large separation from all atoms in the system because of two factors: the presence of very diffuse basis functions in the basis set and the fact that within the theoretical method used the energy of the neutral system is lower than that of the negative ion. ${ }^{54}$ However, in our case this concerns only the HF and CASSCF results; the methods taking into account the electronic correlation from the beginning (including the DFT level of theory) produce a stable negatively charged system.

Removal of diffuse functions from the second-layer atoms (B4a basis set) leads to a reduction of contributions from delocalized states; in this case, we were able to find active space and number of roots combinations giving a satisfactory groundstate energy for $\mathrm{N}_{2} \mathrm{~V}^{-}$, lower than the energy of the neutral system. Nevertheless, the energy difference between them is too small (Table 6), indicating that the wave function quality for the negatively charged system is worse than that for the neutral one. As a result, the calculated excitation energies for $\mathrm{N}_{2} \mathrm{~V}^{-}$are too low, and the $\mathrm{d} E / \mathrm{d} s$ values are too high. Additional basis set reduction (B3a basis set) leads to better results, but 
TABLE 7: Vertical Excitation Energies of $\mathbf{N}_{2} \mathbf{V}^{0}$ and $\mathbf{N}_{2} \mathbf{V}^{-}$Defects Calculated at the CASPT2 Level ${ }^{a}$

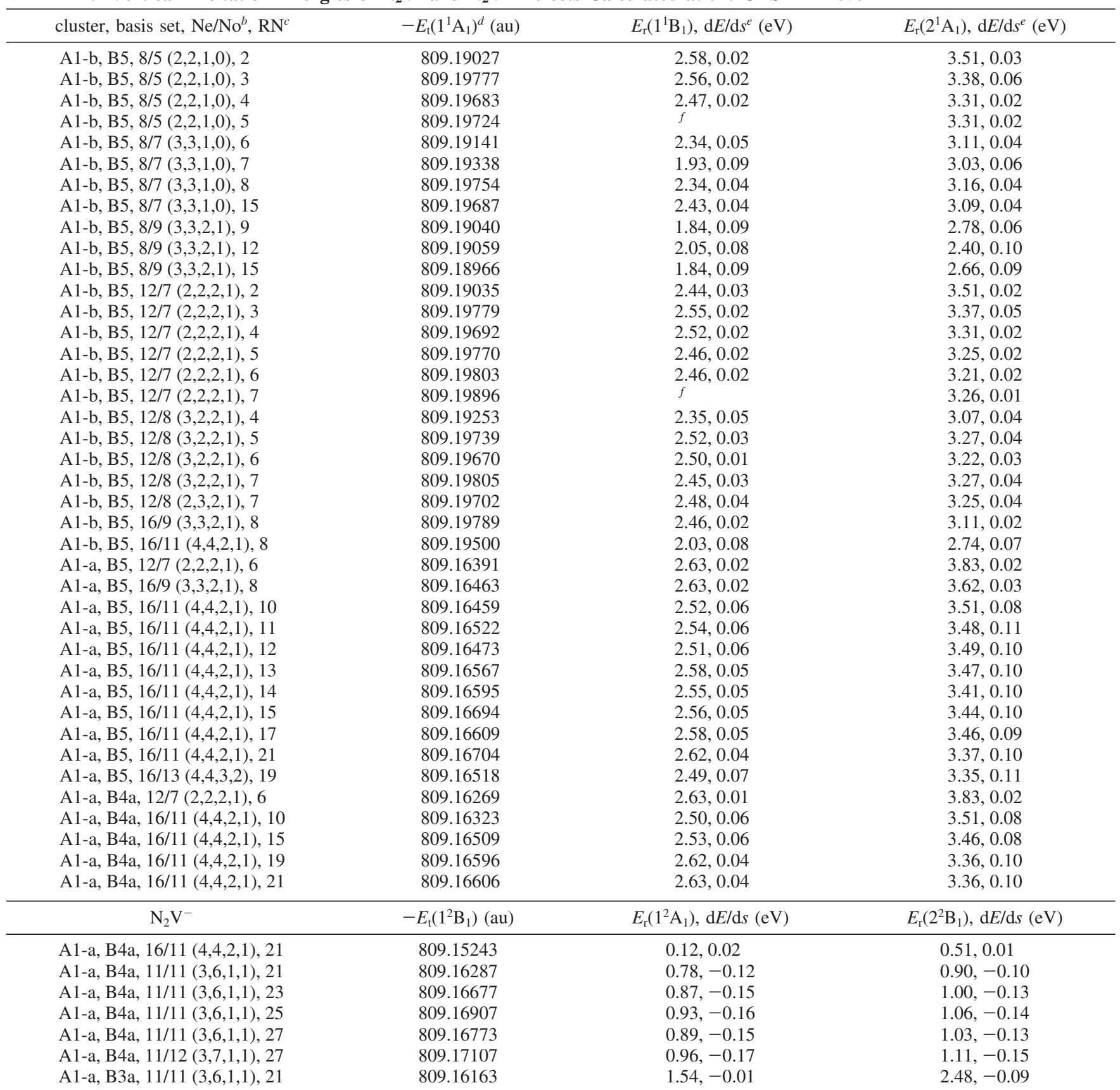

${ }^{a}$ Basis set notation is the following. B5: aug-cc-pVDZ + diffuse sp functions $(0.015)$ for vacancy-related atoms, 6-31G* $+\mathrm{s}(0.010)$ for atoms from the second layer, and 6-31G for all other atoms. B4a: B5 without diffuse s $(0.010)$ functions for atoms from the second layer. B3a: B4a without sp (0.015) for vacancy-related atoms. ${ }^{b} \mathrm{Ne} / \mathrm{No}$ are numbers of active electrons and active orbitals. In parentheses, the numbers of active orbitals are given for each irreducible representation, $A_{1}, B_{1}, B_{2}$, and $A_{2}$, within $C_{2 v}$ symmetry. ${ }^{c} \mathrm{RN}$ is the number of calculated roots. ${ }^{d} E_{\mathrm{t}}$ is the total energy of the ground state. ${ }^{e} E_{\mathrm{r}}$ is the relative energy of an excited state $(\mathrm{eV})$, and $\mathrm{d} E / \mathrm{d} s$ denotes derivatives of excitation energy with respect to shift value. ${ }^{f}$ More roots are required than the number of available configurations.

this is likely due to error cancellation because the ground-state energy with this basis set is higher (Table 6).

We have tried several different combinations of the active space and number of roots (Table 7). In the best available results presented in Table 6, the ground-state wave function is constructed from four CASSCF roots with a maximal contribution from the 19th root, but at the CASPT2 level, it becomes nearly single-determinant, with the largest CI coefficient of 0.98 (220/2000u0/2/2) corresponding to the electronic arrangement with a half-filled antibonding $(\mathrm{C}-\mathrm{C}) \mathrm{b}_{1} \mathrm{MO}$. The first excited state $\left(1^{2} \mathrm{~A}_{1}\right)$ is two-determinant, with the leading contributions of $0.86(22 u / 200000 / 2 / 2)$ and $0.37(20 u / 200020 / 2 / 2)$. The composition of the $2^{2} \mathrm{~B}_{1}$ state is $0.79(220 / 2 \mathrm{u} 0000 / 2 / 2)+0.38$ $(200 / 2 \mathrm{u} 0020 / 2 / 2)-0.33(220 / 20 \mathrm{u} 000 / 2 / 2)$. These results indicate that the initial ground-state wave function was closer to that of an excited state, and its reorganization at the PT2 level is rather significant. It is possible that further extension of the active space and use of a larger number of CASSCF roots can improve the quality of the ground-state wave function, but the improvement is found to be very small when one more active vacant orbital is added (Table 6). Obviously, the active space extension should be more substantial to achieve a better result, but at the moment this is beyond our computational facilities. Another option is to use methods that do not have limitations 
imposed by active space selection; for instance, it would be worthwhile to test the MRDCI approach ${ }^{55}$ for the $\mathrm{N}_{2} \mathrm{~V}^{-}$system.

The ground $1^{2} \mathrm{~A}_{1}$ state of the $\mathrm{N}_{3} \mathrm{~V}^{0}$ defect is purely singledeterminant with the coefficient of 0.997 for the leading configuration. The first excited state is $1^{2} \mathrm{E}$ (Table 6), where the leading determinant with the coefficient of 0.9 is $(22 \mathrm{u} 2000 /$ $22200)$ or $(2222000 / 22 \mathrm{u} 00)$ for the $\mathrm{A}^{\prime}$ or $\mathrm{A}^{\prime \prime}$ components, respectively, where the orbital configuration is described in terms of irreducible representations of the $\mathrm{C}_{\mathrm{s}}$ point group. This arrangement corresponds to electronic transfer from the antibonding combination of nitrogen lone pairs (e HOMO) to the dangling bond of the 3 -fold-coordinated $\mathrm{C}$ atom ( $\left.\mathrm{a}_{1} \mathrm{SOMO}\right)$. Meanwhile, the (22uud00/22200) or (222ud00/22u00) configurations with coefficients of $\sim 0.34$, corresponding to electronic transitions from e HOMO to $\mathrm{a}_{1}$ LUMO, also contribute substantially. The wave function of the second excited state $2^{2} \mathrm{~A}_{1}$ is more complicated with the following leading configurations: $0.70(222000 \mathrm{u} / 22200)-0.54(22200 \mathrm{u} 0 / 22200)-0.25(\mathrm{u} 220 \mathrm{~d} 0 \mathrm{u} /$ $22200)+0.25(\mathrm{u} 220 \mathrm{du} 0 / 22200)+0.22(222 \mathrm{u} 000 / 22200)$. This corresponds to electronic transition from SOMO with admixture of that from the lower $a_{1}$ MO to diffuse empty $a_{1}$ orbitals. It is likely that the calculated energy difference between $1^{2} \mathrm{~A}_{1}$ and $1^{2} \mathrm{E}$ is overestimated, and an extension of the model cluster can slightly lower the energy of the rather diffuse $1^{2} \mathrm{~A}_{1}$ state. Finally, the CASPT2 results are qualitatively the same as those obtained by the TD-DFT method. The present calculations allow us to conclude that the first optical excitation occurs to the $2^{2} \mathrm{~A}_{1}$ state because the oscillator strength for the $2^{2} \mathrm{~A}_{1} \leftarrow 1^{2} \mathrm{~A}_{1}$ transition is significantly higher than that for $1^{2} \mathrm{E} \leftarrow 1^{2} \mathrm{~A}_{1}$ (Table 4). To some extent, this is in agreement with Rand and DeShazer's proposition $^{2}$ but with a reversed order of the first and second excited states having similar energies. So as the energies of these states are close, our modeling is unable to determine their order unambiguously. One can expect that the geometry relaxation and Stokes shifts will be moderate but different for the $2^{2} \mathrm{~A}_{1}$ and $1^{2} \mathrm{E}$ states. It will be worth investigating whether the geometry relaxation is able to separate these states; in such a case, the corresponding PL band would be split into two components with different irradiative lifetimes, but the intensity of the $1^{2} \mathrm{E} \leftarrow 1^{2} \mathrm{~A}_{1}$ component would be small.

Conclusions. Our calculations show that changes of the geometric structure in the $\mathrm{N}_{2} \mathrm{~V}^{0}, \mathrm{~N}_{2} \mathrm{~V}^{-}$, and $\mathrm{N}_{3} \mathrm{~V}^{0}$ defects in diamond in their ground electronic states compared to those in the defectless system are approximately the same as those found earlier for the $\mathrm{NV}^{0}$ and $\mathrm{NV}^{-}$defects. ${ }^{39}$ In particular, the vacancyrelated atoms are shifted away from the vacancy center by $\sim 0.1$ $\AA$ in the largest model clusters containing 50 atoms. Simultaneously, the bonds between the vacancy-related atoms and their neighbors tend to shorten, whereas the bonds between atoms of the second and third layers around the vacancy slightly lengthen. The positions of atoms from the second layer remain nearly unchanged, indicating a local character of geometry relaxation due to the defects.

In the ground states of the defects, the highest occupied MOs are constructed from the stretched $\left(\mathrm{N}_{2} \mathrm{~V}\right)$ or broken $\left(\mathrm{N}_{3} \mathrm{~V}\right) \mathrm{C}-\mathrm{C}$ bond and nonbonding combinations of nitrogen lone pairs. These MOs participate in the formation of the lowest excited states. In contrast to the $\mathrm{NV}^{-}$and $\mathrm{NV}^{0}$ defects, nitrogen lone pairs are actively involved in low-lying electronic excitations in the $\mathrm{N}_{2} \mathrm{~V}^{0}$ and $\mathrm{N}_{3} \mathrm{~V}^{0}$ systems, in addition to the dangling bonds of 3-foldcoordinated carbon atoms around the vacancy. The ground states of the defects are mainly single-determinant for all of the systems, but the excited states usually possess at least two leading configurations in the wave function.
The $\mathrm{C}-\mathrm{C}$ antibonding $\mathrm{MO}$ in $\mathrm{N}_{2} \mathrm{~V}^{0}$ and the broken $\mathrm{C}-\mathrm{C}$ bond in $\mathrm{N}_{3} \mathrm{~V}^{0}$ participate in the formation of the lowest excited states as accepting orbitals. The diffuse vacancy-related MOs are also involved in the lowest states of the $\mathrm{N}_{2} \mathrm{~V}^{-}$and $\mathrm{N}_{3} \mathrm{~V}^{0}$ defects and in the third, fourth, and higher states of $\mathrm{N}_{2} \mathrm{~V}^{0}$. Normally, the first excited states have a valence character, but the diffuse states are rather close in energy, especially for $\mathrm{N}_{3} \mathrm{~V}^{0}$. Because of this, CASSCF calculations give energies of several diffuse states lower than those of valence states. CASPT2 calculations are generally able to correct this error, but one has to compute a large number of roots in CASSCF. Therefore, rather high CASSCF states can contribute to the lowest states at the CASPT2 level. Multireference approaches using the entire set of molecular orbitals instead of a limited active space, like MRDCI ${ }^{55}$ may prove to be more convenient for these and similar systems.

The CASPT2 and TD-DFT (B3LYP) methods produce qualitatively similar results for the diamond defects considered here. According to these results, the first optically active excitation in the $\mathrm{N}_{2} \mathrm{~V}^{0}$ defect with the energy of $\sim 2.6 \mathrm{eV}$ is formed by electronic transition from the stretched $\mathrm{C}-\mathrm{C}$ bond to the antibonding $\mathrm{C}-\mathrm{C} \mathrm{MO}$, with additional contribution from a symmetric combination of nitrogen lone pairs. The best calculated value for the vertical excitation energy to the corresponding $1{ }^{1} \mathrm{~B}_{1}$ state, $2.63 \mathrm{eV}$, agrees with experimental band maximum $(2.58 \mathrm{eV})$ assigned to the $\mathrm{H} 3$ system. The additional nonluminescent lines observed around $3.4 \mathrm{eV}$ can be attributed to the $2^{1} \mathrm{~A}_{1} \leftarrow 1{ }^{1} \mathrm{~A}_{1}$ transition to the second excited state of $\mathrm{N}_{2} \mathrm{~V}^{0}$, and again, the calculated excitation energy of $3.36 \mathrm{eV}$ closely reproduces the experimental value. For the negatively charged $\mathrm{N}_{2} \mathrm{~V}^{-}$system, the lowest excitation to the $1^{2} \mathrm{~A}_{1}$ state is predicted to occur from the singly occupied antibonding $b_{1}$ MO to the empty diffuse $a_{1}$ orbital. Because the initial CASSCF wave function is of a rather poor quality in this case, the CASPT2 calculated excitation energies for $\mathrm{N}_{2} \mathrm{~V}^{-}$, $\sim 0.9 \mathrm{eV}$ are somewhat underestimated; experimentally, the absorption and PL system $\mathrm{H} 2$ assigned to this defect has ZPL at $1.26 \mathrm{eV}$. The $\mathrm{N}_{3} \mathrm{~V}^{0}$ defect has a quite simple $1^{2} \mathrm{~A}_{1}$ ground state with the single electron localized at the dangling bond of the vacancy-related $\mathrm{C}$ atom attached to the vacancy center $\left(\mathrm{a}_{1}\right.$ SOMO). The lowest excited states of $\mathrm{N}_{3} \mathrm{~V}^{0}, 2^{2} \mathrm{~A}_{1}$, and $1^{2} \mathrm{E}$, corresponding to the transitions from SOMO to diffuse LUMO and from the nonbonding combination of nitrogen lone pairs to SOMO, respectively, have close energies of about $3.1-3.3 \mathrm{eV}$, in agreement with the experimental PA band maximum at $\sim 3$ $\mathrm{eV}$. Oscillator strength is calculated to be higher for the $2^{2} \mathrm{~A}_{1} \leftarrow 1^{2} \mathrm{~A}_{1}$ transition, which therefore should give a larger contribution to the lowest PA band for this defect. The results of our calculations for $\mathrm{N}_{3} \mathrm{~V}^{0}$ do not agree with those obtained at the LSDA level ${ }^{37,40}$ but are in accord with the assignment proposed by Rand and DeShazer, ${ }^{2}$ except the order of the first (E-type) and the second (A-type) excited states is reversed. Nevertheless, the difference between the energies of these states is rather small, and the present calculations generally support Rand and DeShazer's description of the N3 system associated with the $\mathrm{N}_{3} \mathrm{~V}^{0}$ defect.

The calculated excited state energies associated with multiple $\mathrm{N}$ defects presented in this paper are found to be in the same energy range as most of the single $\mathrm{N}$ defect energies computed earlier. ${ }^{41}$ This complicates an unambiguous assignment of the experimental absorption bands for nitrogen vacancy defects in diamond. For example, the $1^{1} \mathrm{~A}_{1} \leftarrow 1^{1} \mathrm{~B}_{1}$ transition in the $\mathrm{N}_{2} \mathrm{~V}^{0}$ defect with the energy of $\sim 2.6 \mathrm{eV}$ is sandwiched between the $1^{2} \mathrm{E} \leftarrow 1^{2} \mathrm{~A}_{2}(\sim 2.4 \mathrm{eV})$ and $1^{2} \mathrm{E} \leftarrow 2^{2} \mathrm{E}(2.7-2.8 \mathrm{eV})$ transitions 
in the $\mathrm{NV}^{0}$ system, and several excited states for $\mathrm{NV}^{-}$are also found in the energy range of $2-3 \mathrm{eV}$, with the $1^{2} \mathrm{~A}_{2} \leftarrow 5^{3} \mathrm{E}(\sim 2.7)$ excitation having a significant oscillator strength. Thus, we can conclude that multiple $\mathrm{N}$ vacancies have excited states with energies in the same region as single $\mathrm{N}$ defects, and multiple $\mathrm{N}$ defects could be the origin for some of the bands observed experimentally. Meanwhile, our calculations demonstrate that there exist substantial differences in the electronic structures as well as in the symmetries of the excited states of $\mathrm{NV}, \mathrm{NV}_{2}$, and $\mathrm{NV}_{3}$, which may be potentially probed by using a polarized light.

Acknowledgment. The authors acknowledge the Academia Sinica and National Science Council of Taiwan, ROC for financial support. Partial support from Florida International University is also appreciated.

\section{References and Notes}

(1) Field, J. E., Ed. The Properties of Diamond. Academic Press: London and New York. 1979.

(2) Rand, S. C.; DeShazer, L. G. Opt. Lett. 1985, 10, 481.

(3) Jelezko, F.; Tietz, C.; Gruber, A.; Popa, I.; Nizovtsev, A.; Kilin, S.; Wrachtrup, J. Single Mol. 2001, 2, 255.

(4) Mainwood, A. Phys. Status Solidi A 1999, 172, 25.

(5) Clark, C. D.; Collins, A. T., Woods, G. S. In The Properties of Natural and Synthetic Diamond, Field, J. E., Ed.; Academic Press: London, 1992, 35.

(6) Davies, G. Phvs. Chem. Carbon 1977, 13, 1.

(7) Kurtsiefer, C.; Mayer, S.; Zarda, P.; Weinfurter, P. Phys. Rev. Lett. 2000, 85, 290.

(8) Martin, J.; Wannemacher, R.; Teichert, J.; Bischoff, L.; Kohler, B. Appl. Phvs. Lett. 1999, 75, 3096.

(9) Brouri, R.; Beveratos, A.; Poizat, J.-P.; Grangier, P. Phvs. Rev. A 2000, 62, 0683171-1.

(10) Gisin, N.; Ribordy, G.; Tittel, W.; Zbinden, H. Rev. Mod. Phys., 2002, 74, 145

(11) Yu, S. J.; Kang, M. W.; Chang, H. C.; Chen, K. M.; Yu, Y. C. J. Am. Chem. Soc. 2005, 127, 17604.

(12) Woods, G. S.; van Wyk, J. A.; Collins, A. T. Philos. Mag. B 1990, 62,589 .

(13) Farrer, R. G. Solid State Commun. 1969, 7, 685.

(14) Smith, W. V.; Sorokin, P. P.; Gelles, I. L.; Lasher, G. J. Phvs. Rev. 1959, 115,1546

(15) Lawson, S. C.; Kanda, H. J. Appl. Phys. 1993, 73, 6.

(16) Gruber, A.; Drabensted, A.; Tietz, C.; Fleury, L.; Wrachtrup, J.; von Borczyskowski, C. Science 1997, 276, 2012.

(17) Drabenstedt, A.; Fleury, L.; Tietz, C.; Jelezko, F.; Kilin, S.; Nizovtsev, A.; Wrachtrup, J. Phvs. Rev. B, 1999, 60, 11503.

(18) Kilin, S. Ya.; Nizovtsev, A. P.; Maevskaya, T. M.; Drabenstedt, A.; Wrachtrup, J. J. Lumin. 2000, 86, 201.

(19) Wrachtrup, J.; Kilin, S. Ya.; Nizovtsev, A. P. Opt. Spectrosc. 2001, $91,460$.

(20) Jelezko, F.; Popa, I.; Gruber, A.; Tietz, C.; Wrachtrup, J.; Niezovtsev, A.; Kilin, S. Appl. Phvs. Lett. 2002, 81, 2160.

(21) Davies, G.; Hamer, M. F. Proc. Roy. Soc. London 1976, A348, 285.

(22) Mita, Y. Phvs. Rev. B, 1996, 53, 11360

(23) Martin, J. P. D. J. Lumin. 1999, 81, 237.
(24) Dumeige, Y.; Treussart, F.; Alleaume, R.; Gacoin, T.; Roch, J.-F.; Grangier, P. J. Lumin. 2004, 109, 61.

(25) Treussart, F.; Jacues, V.; Wu, E.; Gacoin, T.; Granier, P.; Roch, J.-F. Physica B 2006, 376-377, 926.

(26) Iakoubovskii, K.; Adriaenssens, G. J.; Nesladek, M.; Stals, L. M. Diamond Relat. Mater. 1999, 8, 717.

(27) Iakoubovskii, K.; Adriaenssens, G. J.; Dogadkin, N. N.; Shiryaev, A. A. Diamond Relat. Mater. 2001, 10, 18.

(28) Iakoubovskii, K.; Adriaenssens, G. J. Phvs. Rev. B 2000, 61, 10174.

(29) Martin, J. P. D.; Manson, N. B.; Doetschman, D. C.; Sellars, M. J.; Neuhaus, R.; Wilson, E. J. Lumin. 2000, 86, 355.

(30) Nizovtsev, A. P.; Kilin, S. Y.; Jelezko, F.; Gruber, A.; Tietz, C.; Wrachtrup, J. Opt. Spectrosc. 2003, 94, 848. 245.

(32) Lenef, A.; Brown, S. W.; Redman, D. A.; Rand, S. C. Phvs. Rev. B 1996, 53, 13427.

(33) Chang, H. C.; Chen, K.; Kwok, S. Astrophvs. J. 2006, 639, L63.

(34) Lenef, A.; Rand, S. C. Phvs. Rev. B 1996, 53, 13441.

(35) Goss, J. P.; Jones, R.; Briddon, P. R.; Davies, G.; Collins, A. T.; Mainwood, A,; van Wyk, J. A.; Baker, J. M.; Newton, M. E.; Stoneham,

A. M.; Lawson, S. C. Phys. Rev. B 1997, 56, 16031.

(36) Lenef, A.; Rand, S. C. Phvs. Rev. B 1997, 56, 16033.

(37) Goss, J. P.; Jones, R.; Breuer, S. J.; Briddon, P. R.; Öberg, S. Phvs. Rev. Lett. 1996, 77, 3041.

(38) Luszczek, M.; Laskowski, R.; Horodecki, P. Physica B 2004, 348, 292.

(39) Lin, Chih-Kai.; Wang, Yi-Hsieh.; Chang, Huan-Cheng.; Hayashi, M.; Lin, S. H. J. Chem. Phvs., 2008, 129, 124714.

(40) Zyubin, A. S.; Mebel, A. M.; Chang, H. C.; Lin, S. H. Chem. Phvs. Lett. 2008, 462, 251.

(41) Zyubin, A. S.; Mebel, A. M.; Hayashi, M.; Chang, H. C.; Lin, S. H. J. Comput. Chem. 2009, 30, 119.

(42) Jones, R.; Goss, J. P.; Briddon, P. R.; Öberg, S. Phys. Rev. B, 1997, 56, R1654.

(43) Frisch, M. J.; Trucks, G. W.; Schlegel, H. B. Gaussian 03, Revision C.2, Gaussian, Inc.: Pittsburgh PA, 2003.

(44) Zakrzewski, G.; von Niessen, W. J. Comput. Chem. 1993, 14, 13.

(45) Zyubin, A. S.; Mebel, A. M. J. Comput. Chem. 2003, 24, 692.

(46) Werner, H.-J.; Knowles, P. J. J. Chem. Phys. 1985, 82, 5053.

(47) Werner, H.-J.; Knowles, P. J.; Almlöf, J.; Amos, R. D.; Deegan, M. J. O.; Elbert, S. T.; Hampel, C.; Meyer, W.; Peterson, K.; Pitzer, R.; Stone, A. J.; Taylor, P. R.; Lindh, R. Molpro, version 2008.1; Molpro, http:// www.molpro.net, 2008.

(48) Raghavachari, K.; Ricci, D.; Pacchioni, G. J. Chem. Phys. 2002, 116,825 .

(49) Tozer, D. J.; Handy, N. C. J. Chem. Phys. 1998, 109, 10180.

(50) Chu, X.; Chu, S. I. Phvs. Rev. A 2001, 63, 023411.

(51) Shieh, J.-C.; Chang, J.-I.; Wu, J.-C.; Li, R.; Mebel, A. M.; Handy,

N. C.; Chen, Y.-T. J. Chem. Phys. 2000, 112, 7384.

(52) Andersson, K.; Malmqvist, P. A.; Roos, B. O. J. Chem. Phvs. 1992, 96, 1218.

(53) Karlström, G.; Lindh, R.; Malmqvist, P.-Å.; Roos, B. O.; Ryde, U.; Veryazov, V.; Widmark, P.-O.; Cossi, M.; Schimmelpfennig, B.; Neogrady, P.; Seijo, L. Comput. Mater. Sci. 2003, 28, 222.

(54) Mebel, A. M.; Lin, S. H.; Pinnaduwage, L. A. Chem. Phys. Lett. $1998,285,114$.

(55) Buenker, R. J.; Peyerimhoff, S. D. Theor Chim Acta 1975, 39, 217.

(56) Wells, A. F. Structural Inorganic Chemistry; Oxford University Press: Oxford, U.K., 1984, Vol. B3.

JP9012703 